\title{
Comparison of capecitabine and tegafur/gimeracil/oteracil $(S-1)$ in the treatment of advanced breast carcinoma in the elderly
}

\author{
Dong-Xing Zheng ${ }^{1 *}$, Ji-Hai Jin², Yu-Juan Liư ${ }^{3}$ \\ ${ }^{1}$ Oncology Department II, ${ }^{2}$ Breast Surgery, ${ }^{3}$ Department of Pediatrics, Binzhou People's Hospital, Binzhou, Shandong, 256600, \\ PR China \\ *For correspondence: Email: zhengdx5566@163.com
}

\begin{abstract}
Purpose: To analyse and compare the clinical effects and safety of capecitabine and tegafur/gimeracil/oteracil (S-1) in the treatment of advanced breast carcinoma.

Methods: Eighty-four metastatic breast cancer elderly patients for whom first or second-line treatment had failed, were selected from among those admitted to the oncology ward of Binjiang People's Hospital, China between January 2014 and June 2015. They were randomly divided into S-1 group ( $n=$ 41) and capecitabine group $(n=41)$ and received varying doses of those drugs according to body surface area. Clinical effects, progression-free survival, and incidence of adverse reactions were compared for the two groups following treatment.

Results: Disease control rate (CR) in S-1 group was $55.6 \%$, much higher than $35.1 \%$ observed for capecitabine group $(p<0.05)$. The disease control rate for the $S-1$ group was $93.7 \%$, also much higher than the $70.6 \%$ found in capecitabine group. Survival analysis showed that the median survival times of the two groups did not differ significantly $(p>0.05)$. Furthermore, some adverse reactions such as myelosuppression and lack of strength, did not differ significantly between the two groups $(p>0.05)$, whereas others, including leukopenia, nausea and vomiting and hand-foot syndrome were more serious and frequent in capecitabine group than in $S-1$ group $(p<0.05)$.

Conclusion: Monotherapy with S-1 is more effective than that with capecitabine. Adverse reactions are minimal for both drugs.
\end{abstract}

Keywords: Breast carcinoma, Capecitabine, S-1, Adverse reactions, Myelosuppression, Leukopenia, Hand-foot syndrome

\begin{abstract}
This is an Open Access article that uses a funding model which does not charge readers or their institutions for access and distributed under the terms of the Creative Commons Attribution License (http://creativecommons.org/licenses/by/4.0) and the Budapest Open Access Initiative (http://www.budapestopenaccessinitiative.org/read), which permit unrestricted use, distribution, and reproduction in any medium, provided the original work is properly credited.

Tropical Journal of Pharmaceutical Research is indexed by Science Citation Index (SciSearch), Scopus, International Pharmaceutical Abstract, Chemical Abstracts, Embase, Index Copernicus, EBSCO, African Index Medicus, JournalSeek, Journal Citation Reports/Science Edition, Directory of Open Access Journals (DOAJ), African Journal Online, Bioline International, Open-J-Gate and Pharmacy Abstracts
\end{abstract}

\section{INTRODUCTION}

Since the 1980s, breast cancer has had the highest incidence and the sixth-highest mortality rate of all malignant tumours in women. In many cases, these cancers have already progressed to a late stage, some with distant metastases, by the time of initial diagnosis $[1,2]$. Surgery and chemotherapy are the major treatment methods for breast cancer. To extend survival as much as possible, chemotherapy without surgical treatment is more appropriate for late-stage 
breast cancer [3,4]. The most preferred chemotherapeutic drugs are anthracyclines and taxanes, but their toxicity and side effects can severely reduce treatment effectiveness andquality of life for elderly patients most such patients are intolerant of combined chemotherapy. Many patients with advanced breast cancer have already experienced treatment failure using the drugs mentioned above. Currently, effective, safe and easy-toadminister therapeutic regimens that can be maintained over the long term are lacking in clinics.

Drugs related to 5-fluorouracil (5-FU) are effective in the treatment of breast cancer. Oral administration of capecitabine is recommended as a standard salvage treatment although adverse reactions such as hand-foot syndrome and gastrointestinal side effects restrict its clinical application [5,6]. Some studies $[7,8]$ have demonstrated significant effects achieved after a single treatment with $\mathrm{S}-1$, with minimal adverse reactions. However most of the research data are from Japan, and few studies have been performed in China. This study sought to compare the curative effects and safety of S-1 and capecitabine in the treatment of patients with advanced breast cancer.

\section{METHODS}

\section{Subjects}

Eighty-two elderly patients with advanced breast cancer admitted to Binzhou People's Hospital, China, between January 2014 and June 2015, were selected. All cases were confirmed as advanced breast cancer, with biopsy-proven invasive ductal carcinomas and distant metastases observed by Computed Tomography (CT) and Magnetic Resonance Imaging (MRI). The subjects were all females aged from 63 to 81 years (median 51 years). All patients were observed to have tumour progression after one or two regimens of chemotherapy. Patients were included if they had measurable lesions according to the response evaluation criteria in solid tumours (RECIST) (version 1.1) [9], and were predicted to have at least a further 6months of survival, with good bone marrow, hepatic, and renal function. Those with rapid disease progression, contraindications to chemotherapy, organ risks, liver and kidney function deficiency, or uncontrolled cerebral metastasis were excluded. The study was approved by the Medical Ethics Committee of Binzhou People's Hospital (approval no. BPH20140104ZDX), and the experiment followed the guidelines of the Declaration of Helsinki [10].

\section{Therapeutic regimen}

The enrolled patients were separated into an S-1 group and a capecitabine group using a random number table, 41 patients were in each group. Drug doses were set according to the body surface area (BSA) of each patient: $80 \mathrm{mg} /$ day for $B S A \leq 1.25 \mathrm{~m}^{2}, 100 \mathrm{mg} /$ day for $B S A>1.25$ $\mathrm{m}^{2}$ but $<1.5 \mathrm{~m}^{2}$, and $120 \mathrm{mg} /$ day for $B S A \geq$ $1.5 \mathrm{~m}^{2}$. Patients in the $\mathrm{S}-1$ group received oral S1 (Shandong New Age Pharmaceutical Co., Ltd., China; State Food and Drug Administration (SFDA) approval number: H20080803) twice daily after breakfast and supper for 28 days, and then stopped taking the drug for 14 days; every 6 weeks was regarded as one cycle. Patients in the capecitabine group received oral capecitabine within $30 \mathrm{~min}$ after breakfast and supper for 14 days, and then stopped taking the drug for 7 days; every 3 weeks was regarded as one cycle. Clinical effect was evaluated every 6 weeks. When the effect was evaluated as complete remission (CR), partial remission (PR), or stable disease (SD), treatment was continued until either tumours developed or intolerable adverse reactions appeared.

\section{Observed features and criteria for indexing therapeutic effect}

The therapeutic effect was evaluated according to RECIST 1.0. In CR all lesions disappeared and did not recur for 4 weeks. Reduction of lesion areas by more than $30 \%$ and the appearance of no new lesions for 4 weeks was considered PR. An increase in lesion area or the appearance of new lesions was considered progressive disease (PD). All patients were reexamined after two courses of treatment. Lesions were measured before and after treatment and were compared to evaluate clinical effects. The overall response rate (ORR) was the sum of percentages of patients with $\mathrm{CR}$ and $\mathrm{PR}$; the disease control rate (DCR) was the sum of percentages of patients with CR, PR and SD. All patients were followed up successfully by telephone and/or by outpatient services. Survival time (in months) were recorded during follow-up and the survival curves were drawn.

\section{Statistical analysis}

SPSS software (ver. 12.0; SPSS Inc., USA) was used for statistical analysis. Categorical data were compared between groups using Chisquare tests. Overall survival time was analysed using Kaplan-Meier plots and compared using log-rank tests. Differences were considered statistically significant if $p<0.05$. 


\section{RESULTS}

\section{Baseline characteristics and treatment conditions}

Of the 82 patients enrolled, $62(75.6 \%)$ had undergone first-line chemotherapy and 20 (24.4 $\%)$ had received second-line chemotherapy. No significant difference was found in general characteristics or previous treatment conditions between the two groups $(p>0.05$; Table 1$)$.

\section{Clinical efficacy}

In S-1 group, the median number of chemotherapy cycles was 3.5 (1 - 11 cycles); after treatment, there were no cases of CR, 13 cases of PR, 14 cases of SD, and 14 cases of $P D$. In the capecitabine group, the median number of chemotherapy cycles was 4 (1 - 17 cycles); after treatment, there were no cases of CR, 8 cases of PR, 11 cases of SD, and 22 cases of PD.

The ORR of the S-1 and capecitabine groups was $31.7 \%(13 / 41)$ and $19.5 \%$ (8/41), respectively $\left(X^{2}=3.963, p<0.05\right)$. The DCR of the two groups was $65.9 \%(27 / 41)$ and $46.3 \%$ (19/41), respectively $\left(X^{2}=6.440, p<0.05\right)$. These differences were statistically significant.
Kaplan-Meier analysis indicated that the median progression-free survival (PFS) for the S-1 group and the capecitabine group was 5.5 and 4.5 months, respectively (95\% confidence intervals: 4.7 - 6.3 and 2.4 - 5.6 months); this difference was not statistically significant $\left(\mathrm{X}^{2}=0.219, p>\right.$ 0.05; Figure 1).

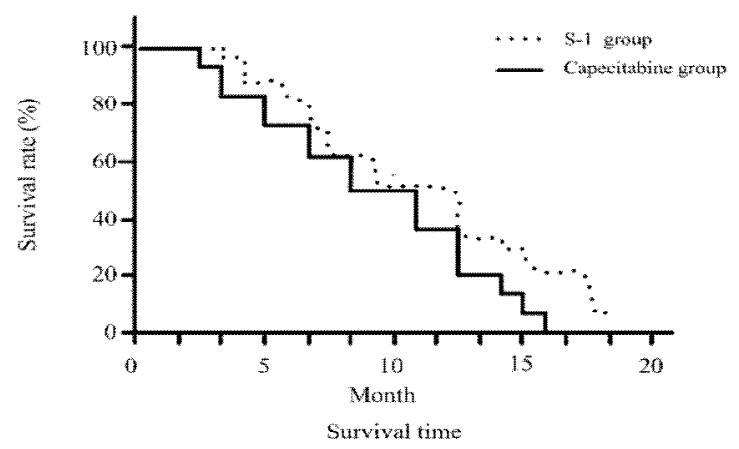

Figure 1: The progression-free survival (PFS) curves of the two groups

\section{Adverse reactions}

Some adverse reactions, such as myelosuppression and lack of strength, did not differ significantly between the two groups ( $p>$ 0.05). Leucopenia, nausea and vomiting, and hand-foot syndrome in the capecitabine group were more serious and more frequent than in the S-1 group $(p<0.05$; Table 2$)$.

\section{Long-term survival rate}

Table 1: Baseline characteristics of the two groups

\begin{tabular}{|c|c|c|c|c|c|}
\hline \multicolumn{2}{|c|}{ Clinical pathological parameter } & $\begin{array}{l}\text { A group } \\
(n=41)\end{array}$ & $\begin{array}{l}\text { B group } \\
(n=41)\end{array}$ & $x^{2}$ & $P$ \\
\hline \multicolumn{2}{|c|}{ Median age (years) } & $69.4 \pm 5.6$ & $70.1 \pm 5.3$ & & \\
\hline \multirow{2}{*}{ Molecular subtyping } & Luminal A & $5(12.2 \%)$ & $7(17.1 \%)$ & & \\
\hline & Luminal B & $16(39.0 \%)$ & $18(43.9 \%)$ & & \\
\hline \multirow{2}{*}{\multicolumn{2}{|c|}{$\begin{array}{l}\text { HER2 overexpression } \\
\text { Triple negative }\end{array}$}} & $9(22.0 \%)$ & $10(24.4 \%)$ & & \\
\hline & & $11(26.8 \%)$ & $6(14.6 \%)$ & 1.921 & $>0.05$ \\
\hline \multirow{2}{*}{ Menstrual state } & Non-menopausal & $13(31.7 \%)$ & $17(41.5 \%)$ & & \\
\hline & Post-menopausal & $28(68.3 \%)$ & $24(58.5 \%)$ & 1.078 & $>0.05$ \\
\hline \multirow{3}{*}{$\begin{array}{l}\text { Number of metastatic lesions } \\
\qquad(\mathrm{n})\end{array}$} & 1 & $12(29.3 \%)$ & $9(22.0 \%)$ & & \\
\hline & $2-3$ & $21(51.2 \%)$ & $24(58.5 \%)$ & 1372 & $>005$ \\
\hline & $\geq 4$ & $8(19.5 \%)$ & $8(19.5 \%)$ & 1.312 & $>0.05$ \\
\hline \multirow{2}{*}{$\begin{array}{l}\text { History of pulmonary } \\
\text { metastasis }\end{array}$} & With & $22(53.7 \%)$ & $24(58.5 \%)$ & & \\
\hline & Without & $19(46.3 \%)$ & $17(41.5 \%)$ & 0.158 & $>0.05$ \\
\hline \multirow{2}{*}{ History of liver metastasis } & With & $25(61.0 \%)$ & $20(48.8 \%)$ & & $>005$ \\
\hline & Without & $16(39.0 \%)$ & $21(51.2 \%)$ & 1.267 & $>0.05$ \\
\hline \multirow{2}{*}{$\begin{array}{l}\text { Chemotherapy cycle number } \\
(\mathrm{n})\end{array}$} & 1 & $27(65.9 \%)$ & $31(75.6 \%)$ & & \\
\hline & 2 & $14(34.1 \%)$ & $10(24.4 \%)$ & 1.178 & $>0.05$ \\
\hline \multirow{2}{*}{$\begin{array}{l}\text { Salvage chemotherapy with } \\
\text { anthracyclines }\end{array}$} & With & $23(56.1 \%)$ & $19(46.3 \%)$ & & \\
\hline & Without & $18(43.9 \%)$ & $22(53.7 \%)$ & 016 & 5 \\
\hline \multirow{2}{*}{$\begin{array}{l}\text { Salvage chemotherapy with } \\
\text { taxanes }\end{array}$} & With & $34(82.9 \%)$ & $30(73.2 \%)$ & & \\
\hline & Without & $7(17.1 \%)$ & $11(26.8 \%)$ & 7 & 15 \\
\hline \multirow{2}{*}{$\begin{array}{l}\text { Salvage chemotherapy with } \\
\text { platinum }\end{array}$} & With & $20(48.8 \%)$ & $22(53.7 \%)$ & & \\
\hline & Without & $21(51.2 \%)$ & $19(46.3 \%)$ & 5 & .05 \\
\hline
\end{tabular}


Table 2: Incidence of adverse reactions between the two groups ( $N, \%)$

\begin{tabular}{lcccc}
\hline Group & A group & B group & $\mathbf{X}^{2}$ & $\boldsymbol{p}$ \\
\hline Myelosuppression & $14(34.1 \%)$ & $13(31.7 \%)$ & 0.027 & $>0.05$ \\
Lack of strength & $29(70.7 \%)$ & $32(78.4 \%)$ & 0.051 & $>0.05$ \\
Leukopenia & $10(24.4 \%)$ & $28(68.3 \%)$ & 7.648 & $<0.05$ \\
Nausea and vomiting & $14(34.1 \%)$ & $39(95.1 \%)$ & 4.847 & $<0.05$ \\
Hand-foot syndrome & $9(22.0 \%)$ & $30(73.2 \%)$ & 5.906 & $<0.05$ \\
\hline
\end{tabular}

Note: A group = S-1 group; B group = capecitabine group

\section{DISCUSSION}

Breast cancer usually becomes metastatic at an advanced stage, at which point it is difficult to treat. Surgical treatment that is suitable at an early stage is not applicable in late-stage disease. The wide distribution of lesions and their significant invasion of surrounding tissues mean that surgery cannot effectively remove them. Therefore, palliative treatment is frequently used for patients with advanced breast cancer, with the intention of extending survival time [11]. Many guidelines recommend single-agent sequential chemotherapy as the first choice for patients with metastatic breast cancer. Although combination chemotherapy may result in higher RRs and longer PFS, it does not confer a survival advantage, and the incidence of toxicity and side effects is significantly increased [12]. Single-agent sequential chemotherapy is thus more beneficial in terms of quality of life. A human pharmacodynamics study [13] suggested that capecitabine, which can be absorbed well, generated a significantly higher concentration of fluorouracil in tumour tissues than in adjacent normal tissues. A study by Ershler WB [14] demonstrated that capecitabine could exert an objective effect on advanced breast cancer and was, moreover, effective and safe. While toxic reactions to capecitabine were controllable in the treatment of weakened patients with advanced breast cancer, there was a high risk of renal function impairment in the elderly [14]. Another study [15] enrolled 236 patients with advanced breast cancer previously treated with anthracyclines and taxanes, and treated them with capecitabine; the RR and median PFS were $23.3 \%$ and 4.7 months, respectively, and remission was sustained in patients with oestrogen receptor-positive cancers and single metastatic lesions. In the present study, the RR of the capecitabine group was $19.5 \%$, and the median PFS was 4.5 months, suggesting good tolerance that was consistent with previous research results. S-1, a fluorouracil-based anticancer drug composed of tegafur, gimeracil, and oteracil potassium, can effectively inhibit dihydropyrimidine dehydrogenase and extend the duration of effective 5-FU concentrations in tumour tissues and surrounding blood. Oteracil potassium can selectively inhibit the activity of 5-
FU metabolic enzymes, reduce the phosphorylation of 5-FU, and lessen its toxic effects in the digestive tract. Compared to capecitabine, S-1 can maintain higher plasma drug concentrations, improve anticancer activity, significantly reduce toxicity, and be administrated conveniently. A Japanese phase II clinical study [16] verified the efficacy and safety of S-1 in the treatment of breast cancer. In that study, 108 patients with advanced breast cancer resistant to taxol were treated with S-1; the RR and median survival time was $41.7 \%$ and $872 \mathrm{~d}$, respectively; grade III - IV toxic reactions included leukopenia $(9.1 \%)$, fatigue $(2.7 \%)$ and poor appetite (3.6 $\%$, yielding S-1 a high safety rating.

Yuan et al [17] carried out a phase II clinical study on 33 patients for whom previous treatment with taxanes and anthracyclines and had failed. As second-line mono-chemotherapy, the median PFS and RR with S-1 were 3.3 months and $33.3 \%$, respectively. The present study found a CR rate for S-1 group of $31.7 \%$, which was much higher than the $19.5 \%$ seen in the capecitabine group; the overall DCR of the S1 group was $65.9 \%$, much higher than the 46.3 $\%$ seen with capecitabine. Some adverse reactions, such as leukopenia, nausea and vomiting, and hand-foot syndrome were more serious in capecitabine group than in S-1 group $(p<0.05)$.

\section{Limitation of the study}

The number of cases enrolled in the study was small, and the observation time was not long. Hence, longer studies with a larger sample size are required to further investigate the clinical effects of capecitabine and S-1.

\section{CONCLUSION}

The findings of this study indicate that S-1 has a higher efficacy than capecitabine, and also that it induced minimal toxicity and side reactions in advanced breast cancer patients for whom previous treatment with anthracyclines and taxanes failed. Therefore, S-1 seems a better choice than capecitabine in the clinical treatment of advanced breast cancer. 


\section{DECLARATIONS}

\section{Conflict of Interest}

The authors declare that no conflict of interest is associated with this work.

\section{Contribution of authors}

We declare that this work was done by the authors named in this article and all liabilities pertaining to claims relating to the content of this article will be borne by the authors. Dong-Xing Zheng and Ji-Hai Jin: Study design, data collection and analysis. Ji-Hai Jin and Yu-Juan Liu: Manuscript preparation, drafting and revising. Dong-Xing Zheng: Review and final approval of manuscript.

\section{REFERENCES}

1. Hu W, Shi JY, Sheng Y, Li L. Clinical observation of capecitabine as first-line monotherapy in elderly patients with lla breast cancer. Aced J Sec Mil Med Univ 2009; 30(2): 187-189.

2. Silver DP, Richardson AL, Eklund AC, Wang ZC, Szallasi Z, Li Q, Juul N, Leong CO, Calogrias D, Buraimoh A, et al. Efficacy of neoadjuvant Cisplatin in triple-negative breast cancer. J Clin Oncol 2010; 28(7): 1145-1153.

3. O'Shaughnessy J, Schwartzberg L, Danso MA, Miller KD, Rugo HS, Neubauer M, Robert N, Hellerstedt B, Saleh $M$, Richards $P$, et al. Phase III study of iniparib plus gemcitabine and carboplatin versus gemcitabine and carboplatin in patients with metastatic triple-negative breast cancer. J Clin Oncol 2014; 32(34): 3840-3847.

4. Wildiers $H$, Mauer $M$, Pallis A, Hurria A, Mohile SG, Luciani A, Curigliano G, Extermann M, Lichtman SM, Ballman $K$, et al. End points and trial design in geriatric oncology research: a joint European organization for research and treatment of cancer-Alliance for Clinical Trials in Oncology-International Society of Geriatric Oncology position article. J Clin Oncol 2013; 31(29): 3711-3718.

5. Hamaker ME, Seynaeve C, Nortier JW, Wymenga M, Maartense E, Boven E, van Leeuwen-Stok AE, de Rooij $S E$, van Munster $B C$, Smorenburg $C H$. Slow accrual of elderly patients with metastatic breast cancer in the Dutch multicentre OMEGA study. Breast 2013; 22(4): 556-559.

6. Li JY, Ji CF, Chen J, Tan QH. Clinical observation of capecitabine in the maintenance treatment of advanced breast cancer. Chin Oncol 2014; 24(5): 381-382.

7. Telli ML, Jensen KC, Vinayak S, Kurian AW, Lipson JA, Flaherty PJ, Timms K, Abkevich V, Schackmann EA, Wapnir IL, et al. Phase II study of gemcitabine, carboplatin, and iniparib as neoadjuvant therapy for triple-negative and BRCA1/2 mutation-associated breast cancer with assessment of a tumor-based measure of genomic instability. J Clin Oncol 2015; 33(17): 18951901.

8. Yamamoto $D$, Iwase $S$, Tsubota $Y$, Ariyoshi $K$, Kawaguchi $T$, Miyaji $T$, Sueoka $N$, Yamamoto $C$, Teramoto S, Odagiri $\mathrm{H}$, et al. Randomized study of orally administered fluorinated pyrimidines (capecitabine versus S-1) in women with metastatic or recurrent breast cancer: Japan Breast Cancer Research Network 05 Trial. Cancer Chemother Pharmacol 2015; 75(6): 1183-1189.

9. Therasse P, Arbuck SG, Eisenhauer EA, Wanders J, Kaplan RS, Rubinstein L, Verweij J, Van Glabbeke M, van Oosterom AT, Christian MC, et al. New guidelines to evaluate the response to treatment in solid tumors. European Organization for Research and Treatment of the Cancer, National Cancer Institute of the United States, National Cancer Institute of Canada. J Natl Cancer Inst 2000; 92(3): 205-216.

10. Declaration of Helsinki. The 59th World Medical Conference, 2008.

11. Wu MH, Wang YJ. Clinical observation of gemcitabine in combination with capecitabine in the treatment of advanced breast cancer with drug resistance to antharcyclines and taxanes. Chin J Clin 2011; 5(2): 130132.

12. Dear RF, McGeechan $K$, Jenkins MC, Barratt $A$, Tattersall MH, Wilcken N. Combination versus sequential single agent chemotherapy for metastatic breast cancer. Cochrane Database Syst Rev 2013; (12): CD008792.

13. Huang HY, Jiang ZF, Wang T, Zhang SH, Bian L, Cao Y, Wu SK, Song ST. Efficacy and safety of regimens of capecitabine-based chemotherapy in the treatment of advanced breast cancer. Chin J Oncol 2011; 33(11): 850-853.

14. Ershler WB. Capecitabine monotherapy: safe and effective treatment for metastatic breast cancer. Oncologist 2006; 11(4): 325-335.

15. Hong JY, Park YH, Choi MK, Jung HA, Lee SJ, Ahn JS, Im YH. Characterization of durable responder for capecitabine monotherapy in patients with anthracycline- and taxane-pretreated metastatic breast cancer. Clin Breast Cancer 2015; 15(5): e287-292.

16. Saek T, Takashima S, Sano M, Horikoshi N, Miura S, Shimizu S, Morimoto K, Kimura M, Aoyama H, Ota J, et al. A phase II study of S-1 in patients with metastatic breast cancer-a Japanese trial by the $S-1$ cooperative study group, breast cancer working group. Breast Cancer 2004; 11(2): 194-202.

17. Yuan P, Di LJ, Liu W, Wan DG, Dai H, Tong ZS, Du F, $X u B H$. Phase II multi-center clinical study on using S-1 to treat advanced breast cancer after resistance to anthracycline and taxane drugs in Chinese patients. Int J Clin Exp Med 2015; 8(2): 3072-3079. 